\title{
Perceptions of tobacco health warnings in China compared with picture and text-only health warnings from other countries: an experimental study
}

\author{
Geoffrey T Fong, ${ }^{1,2}$ David Hammond, ${ }^{1}$ Yuan Jiang, ${ }^{3}$ Oiang Li, ${ }^{1,3}$ Anne C K Quah, ${ }^{1}$ \\ Pete Driezen, ${ }^{1}$ Mi Yan, ${ }^{1}$ for the ITC China Project Team
}

${ }^{1}$ University of Waterloo, Waterloo, Ontario, Canada ${ }^{2}$ Ontario Institute for Cancer Research, Toronto, Ontario, Canada

${ }^{3}$ National Office of Tobacco Control, China Center for Disease Control and Prevention, Beijing, China

\section{Correspondence to} Geoffrey T Fong, Department of Psychology, University of Waterloo, 200 University Avenue West, Waterloo, Ontario, Canada N2L 3G1 gfong@uwaterloo.ca

Received 24 February 2010 Accepted 3 August 2010

\section{(2) UNLOCKED}

This paper is freely available online under the BMJ Journals unlocked scheme, see http:// tobaccocontrol.bmi.com/site/ about/unlocked.xhtml

\section{ABSTRACT}

Objective To assess the perceived effectiveness of cigarette health warnings in China, compared with picture and text-only warnings from other countries. Method 1169 individuals (adult smokers, adult nonsmokers and youth) from four Chinese cities (Beijing, Shanghai, Kunming and Yinchuan) viewed 10 health warnings on cigarette packages, which included (a) the current Chinese text warnings covering $30 \%$ of the front/ back of the pack (introduced October 2008); (b) the former Chinese text warning located on the side of the pack; (c) four picture warnings covering $50 \%$ of the front/back of the pack from Canada (lung cancer), Singapore (mouth disease), Hong Kong (gangrene) and European Union (clogged arteries); and (d) the same four warnings without the picture. Participants rated and ranked the 10 warnings on dimensions including how effective each would be in motivating smokers to quit and in convincing youth not to start smoking.

Results Both Chinese warnings were consistently rated as least effective, with the new Chinese warning rated only slightly higher than the old warning. The picture warnings were consistently ranked or rated as most effective, with the text-only versions in the middle. Results were consistent across subject group, city and sex.

Conclusions (1) Picture warnings are rated as much more effective than the same warnings without pictures. (2) The revised health warnings in China, introduced in October 2008, are only marginally more effective than the previous warning and far less effective than even text warnings from other countries. These results, coupled with population-based evaluation studies, suggest that pictorial warnings would significantly increase the impact of health warnings in China.

Health warnings on tobacco packages constitute an important method to inform and educate the public about the harms of tobacco use. ${ }^{1}$ Health warnings are the focus of Article 11 of the World Health Organization's Framework Convention on Tobacco Control (FCTC), the world's first health treaty, which, as of August 2010, has been ratified by 171 countries inhabited by more than $85 \%$ of the world's population. Article 11 states that warnings shall be no less than $30 \%$ of the front and back of the package. There must be multiple versions of the warnings, which must be rotated, and packs must display information about product constituents. In addition to the minimum requirements, the FCTC recommends that health warnings cover at least
$50 \%$ of the package, include pictures and a distinctive border to make the warning more prominent, and that they appear at the top of the package; these recommendations were incorporated in the Article 11 Guidelines, which were adopted at the Third Conference of the Parties in November $2008 .^{2}$

China ratified the FCTC in October 2005 and has slowly begun to take steps towards implementing the FCTC in this country of over 300 million smokers. Until October 2008, China's text-only health warning was very small and located on the side of the pack, rather than on the front or back. There was just one message: "smoking may harm your health".

In October 2008, China implemented an enhancement of its health warning. The old and new health warnings are shown in figure 1 . The new health warning had the following characteristics: (1) The health warning occupied $30 \%$ of both the front and back, although there were no design elements that set apart the health warning from the rest of the package design; (2) the warning appeared at the bottom rather than at the top of the package; (3) the health warning consists of two very general messages, rather than including information about the specific harms of smoking: "smoking is harmful to your health" and "quit [ting] smoking reduces health risk"; (4) the rotation consists only of a slight change in the second message: "quit[ting] smoking early is good for your health"; the first message remains identical on all packages; and (5) the two-message health warning on the back of all packages is identical to the front but is printed entirely in English (the English warnings included a grammatical error; the verbatim text is corrected above).

Although evaluation studies from the International Tobacco Control Policy Evaluation Project (the ITC Project) have demonstrated the effectiveness of picture warnings relative to text warnings at the population level, ${ }^{1}{ }^{3-8}$ the survey methods used in those evaluation studies have not allowed a more fine-grained and comparative evaluation at the level of the individual warning. Different methods - in particular, experimental studies are best suited to determine the relative effectiveness of specific and individual warnings. In one such example by Peters et $a l^{9}{ }^{9}$ smokers and nonsmokers in the USA were exposed to either Canadian pictorial health warnings or the U.S. text-only health warnings. Peters et al found that the Canadian pictorial warnings elicited significantly greater negative affect and were viewed for 


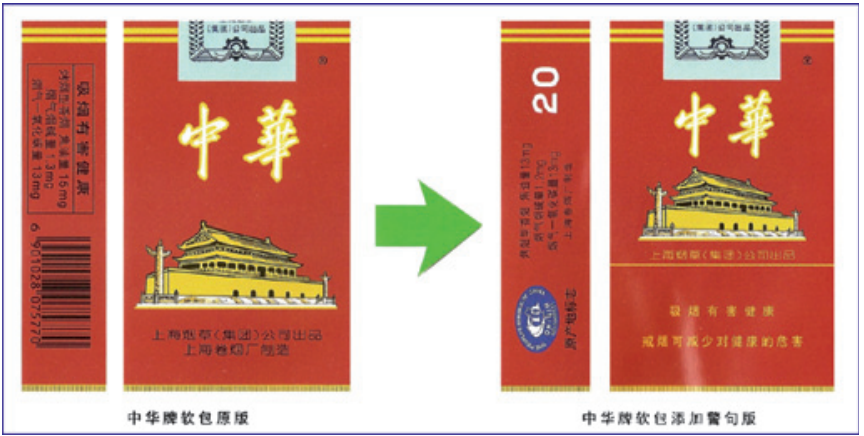

Figure 1 The old (before October 2008) health warning and the new (October 2008) health warning on cigarette packages in China.

a significantly longer time than were the U.S. warnings. Such experimental studies are necessary to examine the impact of specific features of warnings, which would be beneficial for the design of warnings in countries that are in the planning stages.

The objective of this study was to compare the perceptions of Chinese individuals among three groups - adult smokers, adult nonsmokers and youth - of both the new and the old Chinese health warnings as contrasted with four health warnings from other countries/jurisdictions: Hong Kong, Singapore, Canada and the European Union (EU) - in their original form with pictures and in a revised form in which the text of the warning was identical but with the picture removed. Participants rated and ranked the 10 health warnings on a number of important dimensions directly related to public health goals, including perceived effectiveness in motivating smokers to quit and in convincing youth not to start smoking. To test for regional differences, the study was conducted in four cities: Beijing, Shanghai, Kunming and Yinchuan. The study was conducted in January-February 2009. Reports from all four cities indicated that at the time of the study the new warnings had totally or nearly totally replaced the old warnings.

\section{METHOD}

\section{Participants and study design}

The participants were 1169 individuals, who participated in the study during January-February 2009. The study design was a city (four: Beijing, Shanghai, Kunming, Yinchuan) $\times \operatorname{sex}($ two $) \times$ participant group (three: adult smokers, adult nonsmokers, youth (13-17 years old)). Table 1 presents the study design and the number of participants in each of the cells. Table 2 presents descriptive statistics of two participant groups: adult smokers and youth. Reactions to the current health warnings by adult smokers point to their lack of impact: only $28 \%$ to $46 \%$ reported noticing the warnings "often" or "very often" and only $9 \%$ to $13 \%$ reported that the warnings made them think about the health risks of smoking "often" or "very often".

The participants were recruited by local neighbourhood leaders and/or by staff at the local Center for Disease Control (CDC) in

Table 1 Study design and number of participants

\begin{tabular}{|c|c|c|c|c|c|c|c|}
\hline \multirow[b]{2}{*}{ City } & \multicolumn{2}{|c|}{ Adult smoker } & \multicolumn{2}{|c|}{$\begin{array}{l}\text { Adult } \\
\text { nonsmoker }\end{array}$} & \multicolumn{2}{|c|}{$\begin{array}{l}\text { Youth } \\
\text { (13-17 years) }\end{array}$} & \multirow[b]{2}{*}{ Total } \\
\hline & Male & Female & Male & Female & Male & Female & \\
\hline Beijing & 55 & 40 & 39 & 47 & 51 & 45 & 277 \\
\hline Kunming & 50 & 50 & 46 & 50 & 50 & 50 & 296 \\
\hline Shanghai & 51 & 52 & 47 & 50 & 50 & 50 & 300 \\
\hline Yinchuan & 50 & 48 & 48 & 50 & 50 & 50 & 296 \\
\hline Totals & 206 & 190 & 180 & 197 & 201 & 195 & 1169 \\
\hline
\end{tabular}

each city, who conducted the recruitment at neighbourhood association offices (Ju Wei Hui) and at local schools across a broad number of street districts (Jie Dao) throughout each city.

\section{Stimulus materials}

Ten images of Chinese health warnings were created, including the old Chinese health warning (located on the side of the pack) and the new Chinese health warning $30 \%$ on the front of the pack). We created high-quality images of one health warning from each of four countries with picture warnings (Canada, lung cancer; Singapore, mouth disease; Hong Kong, gangrene; EU, clogged arteries). We translated the text into Chinese. For each of the four picture warnings, we created text-only versions by removing the picture.

Using digital image software, each constructed warning was placed on the image of a cigarette pack so that the resulting image was consistent with the Article 11 Guidelines: they occupied $50 \%$ of the top part of the package and each was set apart by a thick black box surrounding the warning. Each of the 10 images (old and new Chinese warnings and the eight constructed warnings) was placed on the cigarette pack of the same brand (Chunghwa) to maintain consistency.

The 10 images were assigned a random number from 1 to 10 to identify each warning to the respondent for the rating and ranking tasks. An image of each pack with that identifying number was printed on photographic paper, so that the size of the pack image was about $57 \times 90 \mathrm{~mm}$, nearly identical to the real pack size of about $55 \times 88 \mathrm{~mm}$.

The full set of 10 images is presented in figure 2 .

\section{Measures}

Prelabel task questionnaire

Each respondent completed a short questionnaire that asked about demographic characteristics (eg, age, sex) and about various attitudes and opinions about smoking. Respondents who were smokers completed additional items that asked about their smoking history and current smoking (eg, cigarettes per day), using standard wording from the ITC surveys in China (see http://www.itcproject.org/research/surveys/itcchina).

\section{Translation task}

The translation task was designed to assess whether the Chinese respondents could understand the back warnings, which, as indicated above, appeared entirely in English. The first sentence was the top message of the new Chinese health warning: "Smoking is harmful to your health". The second sentence was one of the two variations of the bottom message: "Quit smoking early is good for your health" (this ungrammatical English sentence was reproduced verbatim from the text of the warning). The translation task was presented before exposure to any of the health warnings described below, so there was no previous exposure that could have prompted the answers to this translation task.

\section{Label rating task}

Each participant rated each of the 10 health warnings on two dimensions: (a) how effective each label would be in motivating smokers to quit and how effective each label would be in convincing youth not to start smoking. They did so on a fivepoint scale, where $5=$ " extremely effective", 4= "very effective", $3=$ "somewhat effective", 2 ="a little bit effective", and 1="not at all effective" (there were additional rating tasks, eg, emotional reactions and ratings of realism, but the analyses involving those variables are not reported in this paper). 
Table 2 Descriptive statistics for adult smokers and for youth

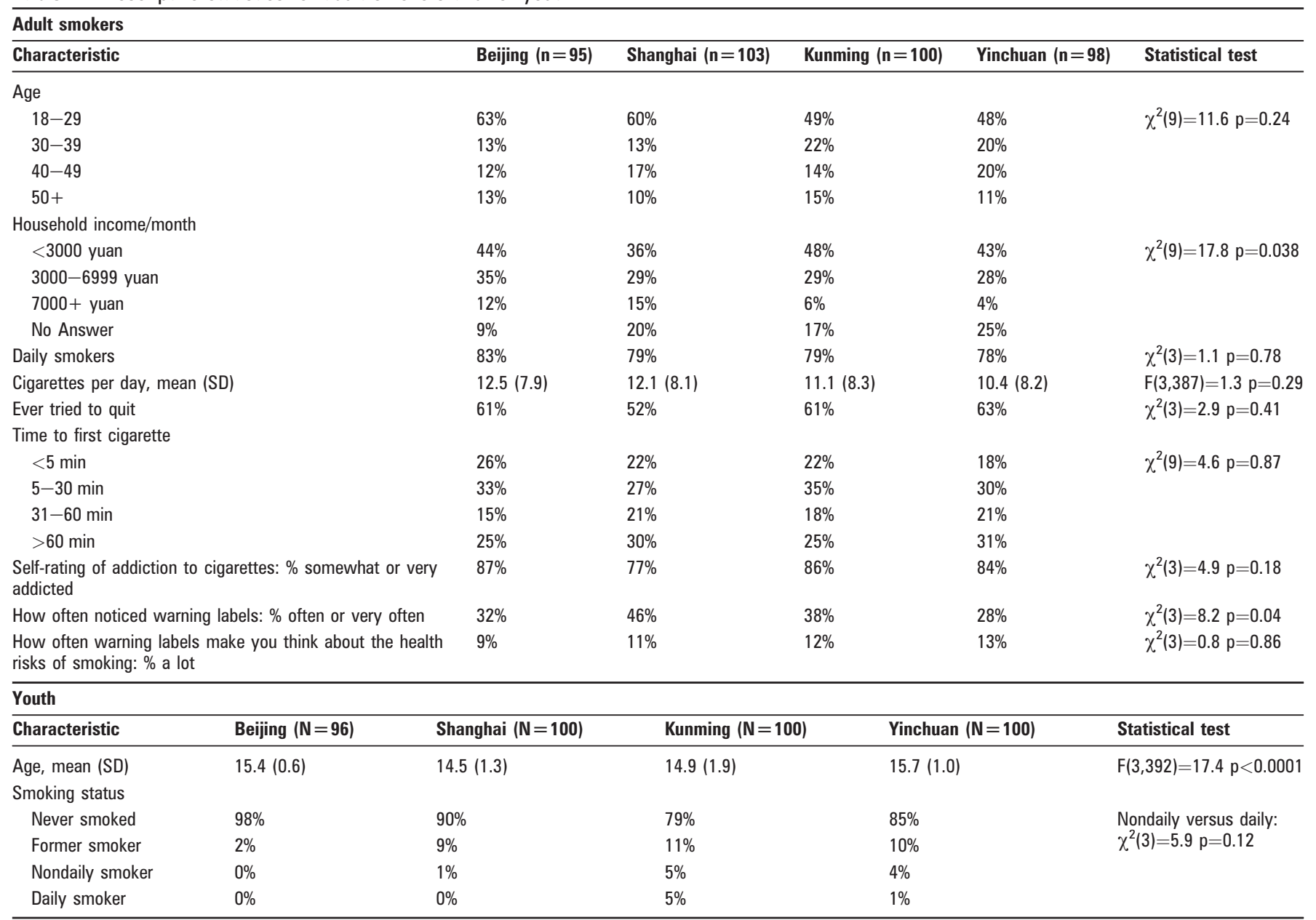

Label ranking task

Each participant rank ordered each of the 10 health warnings on effectiveness on four dimensions: (a) motivating smokers to quit, (b) convincing youth not to start smoking, (c) informing the public about the harms of smoking, and (d) showing that the Chinese government is serious about reducing smoking.
Postlabel task questionnaire

All respondents answered two questions. The first was: "Do you think that cigarette packages should have more health information than they do now, less information, or about the same amount as they do now?" The response categories were "less health information", "about the same" and "more health
Figure 2 Images of health warnings used in the study, including Old and New Chinese health warnings. Note: numbers below each image are the random order numbers assigned to each of the images.

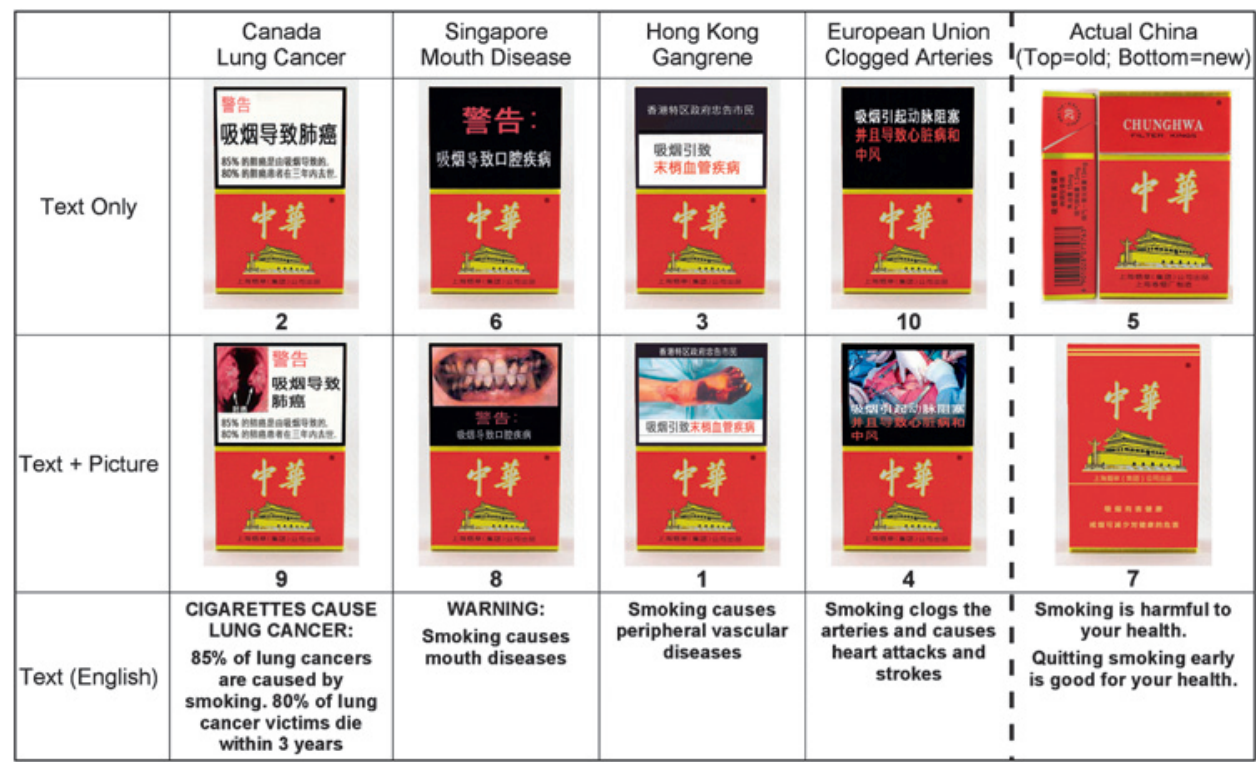


information". The second was "Do you think that the government should include pictures as part of the health warning on cigarette packs?" The response categories were "yes" or "no".

\section{Procedure}

Participants were recruited by local CDC staff in each of the four cities. They participated in small groups at locations such as conference rooms and neighbourhood schools. Upon arrival at the experimental session, participants were placed at a desk or table at sufficient distance from other participants so that their responses could remain confidential. The experimenter (a trained staff member of the local CDC) read the instructions from a written script for each part of the experiment. All experimental sessions across all four cities used the same script.

After the prelabel task questionnaire and translation task were completed, the experimenter called attention to the envelope on each participant's desk or table position. Inside the envelope were the 10 photo cards of the health warnings, randomly numbered 1 to 10 as shown above in figure 2. The experimenter conducted the label ranking task, the label rating task, and the postlabel task questionnaire. The experimenter then verbally debriefed the respondents and gave them a written feedback sheet. Finally, each participant was given 20 yuan in compensation for their participation.

The study protocol and all experimental materials, including the photo images and the questionnaires, were cleared for ethics by the Institutional Review Board of the China National CDC and by the Human Research Ethics Committee at the University of Waterloo.

\section{Data analysis}

Descriptive statistics were conducted on the demographic variables, and differences were tested via $\chi^{2}$ analyses. The rating data were analysed by a mixed-model analysis of variance, with post hoc contrasts conducted to test for differences between individual warnings. Pearson correlation coefficients were computed to examine the degree of consistency between the rating and ranking tasks. All analyses were conducted using SAS V.9.1.

\section{RESULTS}

\section{Ratings of warning effectiveness}

Figure 3 presents the mean effectiveness ratings across all respondents for each of 10 health warnings on the dimension of motivating smokers to quit. The four picture warnings are presented in upward diagonal striped bars; the four text warnings from non-Chinese countries are in solid bars; the two China warnings (the old warning and the new warning) are in downward diagonal striped bars.

There was a substantial difference across the 10 warnings in mean effectiveness, $F(9,10278)=785.32, p<0.0001$. A difference between the means of any two labels of 0.10 scale point is significant at the 0.05 level, a difference between the means of any two labels of 0.13 scale points is significant at the 0.01 level, and a difference of 0.17 scale points is significant at the 0.001 level.

Looking first at the broad categories of warnings, all four of the picture warnings were rated highest on effectiveness in motivating smokers to quit, followed by a large gap of about 0.5 scale point by the four non-Chinese text warnings $(p<0.0001)$, followed by another large gap of 0.6 scale point between the text warnings and the two Chinese warnings $(p<0.0001)$.

Looking within the picture warnings, the Canadian lung cancer warning received the highest rating, followed by the Singapore mouth disease warning, the Hong Kong gangrene warning and the EU clogged arteries warning. All differences between adjacent warnings were significant at the 0.05 level. Among the text warnings, the Canadian lung cancer warning had the highest rating, followed by the EU clogged arteries warning, the Hong Kong gangrene warning and the Singapore mouth disease warning. Finally, the new Chinese warning was significantly more highly rated than the old warning $(p<0.05)$, but much lower in ratings than the lowest-rated text-only warning from the other countries $(p<0.0001)$.

Figure 4 presents the mean effectiveness ratings on the dimension of convincing youth not to start smoking. The identical pattern of results was found. The exact ordinality of the 10 warnings was replicated with the only exception that the
Figure 3 Mean effectiveness ratings of each health warning: "How effective would each label be in motivating smokers to quit?" (All Respondents).




Figure 4 Mean effectiveness ratings of each health warning: "How effective would each label be in convincing youth not to start smoking?" (All respondents).



Canadian lung cancer and Singapore mouth disease picture warnings did not differ significantly at the 0.05 level.

We conducted mixed model ANOVAs to determine whether these ratings varied as a function of the factors in the study design. The results were essentially the same for the ratings for motivating smokers to quit and for convincing youth not to start: (a) there was no difference by city, subject group (smokers, nonsmokers, youth) or sex; (b) there was an enormous effect of warning $(p<0.0001)$ and $(c)$ there were significant interactions for warning $\times$ city $(p<0.0001)$ and for warning $\times$ participant group $(p<0.0001)$ and warning $\times$ sex $(p=0.017)$. The interactions were due almost entirely to variations in the effectiveness ratings among the four pictorial warnings or among the four non-Chinese text warnings rather than due to variation in city, participant group, and sex across the broader categories of pictorial warnings versus text-only warnings. In no subgroup (sex, city, or participant group) did the basic ordering change: the four pictorial warnings were always rated as much more effective than the four non-Chinese text warnings, which in turn were always rated as much more effective than the two Chinese warnings. The two China warnings were always the lowest rated of the 10 warnings.

Because the sample sizes were high, small mean differences can yield statistical significance. To provide some indication of the effect sizes - which are independent of sample size associated with key comparisons of the new Chinese warning and the other warnings, we computed the Cohen's $d$ for the difference between the new Chinese warning and (a) the lowestrated foreign text warning and (b) between the new Chinese warning and the lowest-rated foreign picture+text warning. For ratings of effectiveness for whether the warning motivated smokers to quit, the difference between the new Chinese warning and the lowest rated foreign text warning (Singapore mouth disease) was associated with $\mathrm{d}=0.47$, close to the benchmark of 0.5 , for a "moderate" effect size and the difference between the new Chinese warning and the lowest rated foreign text + picture warning (EU clogged arteries) was associated with $\mathrm{d}=1.36$, way above the benchmark of 0.8 for a "high" effect size. The Cohen's d for the same two differences on convincing youth not to start smoking were very similar: 0.45 and 1.27 , respectively. All other comparisons between the new Chinese warning and any other text or text + picture warning would yield an even higher effect size. These effect size computations demonstrate the pronounced differences in perceived effectiveness between the new Chinese warnings and any of the foreign alternatives, especially those with graphic images.

\section{Ranking of label effectiveness}

The ranking task replicated the findings of the rating task. There were two dimensions on which participants both ranked and rated the 10 labels. Figure 5 presents the mean rankings for effectiveness in motivating smokers to quit, which shows the near identical pattern of results presented in figure 3 for mean ratings.

The chart of mean rankings for effectiveness in convincing youth not to start smoking is presented in figure 6. Although there were some differences in ordering within the four picture warnings (eg, the Singapore mouth disease warning was the highest ranked warning), compared with the mean ratings presented in figure 4, the strong three-level ordering of the warnings was found again. For the mean rankings, the gap between the China warnings and the other text-only warnings was more pronounced than it was for the mean ratings.

The similarity of the ranking and rating tasks was quantified by computing the within-subject correlation between ranking and rating for each respondent. For motivating smokers to quit, the mean correlation between ranking and rating was 0.732 ; for convincing youth not to start smoking, it was 0.704 .

As an illustration of the uniformity of the difference between the picture warnings and the new China warnings, 59\% of all participants ranked the Singapore picture warning as the most effective or the second most effective warning for convincing youth not to start smoking. In contrast, $81 \%$ of all participants ranked the new China warning as either the least effective or the second least effective warning. 
Figure 5 Mean ranking of health warnings on "How effective would each label be in motivating smokers to quit?" (All Respondents).

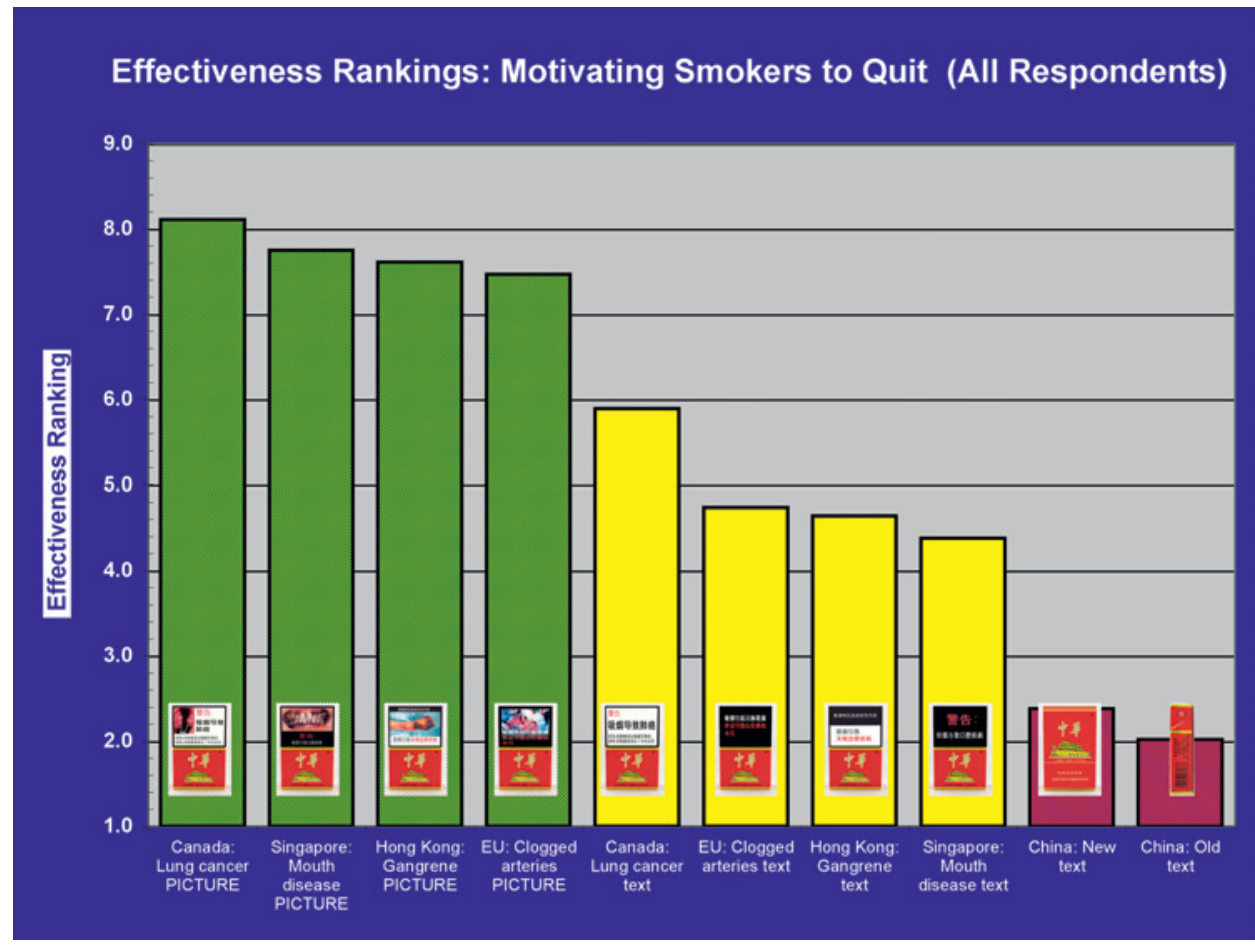

Figure 7 presents the mean rankings of the warnings on how effective the labels were for informing the public of the dangers of smoking. Figure 8 presents the mean rankings of the warnings on effectiveness for showing that the Chinese government is serious about reducing smoking. For both of these measures, the same three-level findings were replicated, although there was a very slight difference in ranking within the levels.

\section{Opinions about what the Chinese warnings should include}

At the end of the study session, participants were asked for their opinions about what the Chinese warnings should include.
Nearly three-quarters of participants $(74.4 \%)$ stated that cigarette packages should have more health information. Only $6.0 \%$ said that cigarette packages should have less health information, same". The opinion that cigarette packages should have more health information was higher in Kunming (77.7\%), Yinchuan (76.0\%), and Shanghai (75.5\%), than it was in Beijing $(67.6 \%)$ (each comparison with Beijing: $\mathrm{p}<0.035$ ). It was highest among youth (81.5\%), followed by adult nonsmokers $(77.5 \%)$ and lowest among adult smokers (64.2\%). Youth and nonsmokers did not differ from each other, but both were, as expected, and $19.6 \%$ said that cigarette packages should have "about the
Figure 6 Mean ranking of health warnings on "How effective would each label be in convincing youth not to start smoking?" (All Respondents).

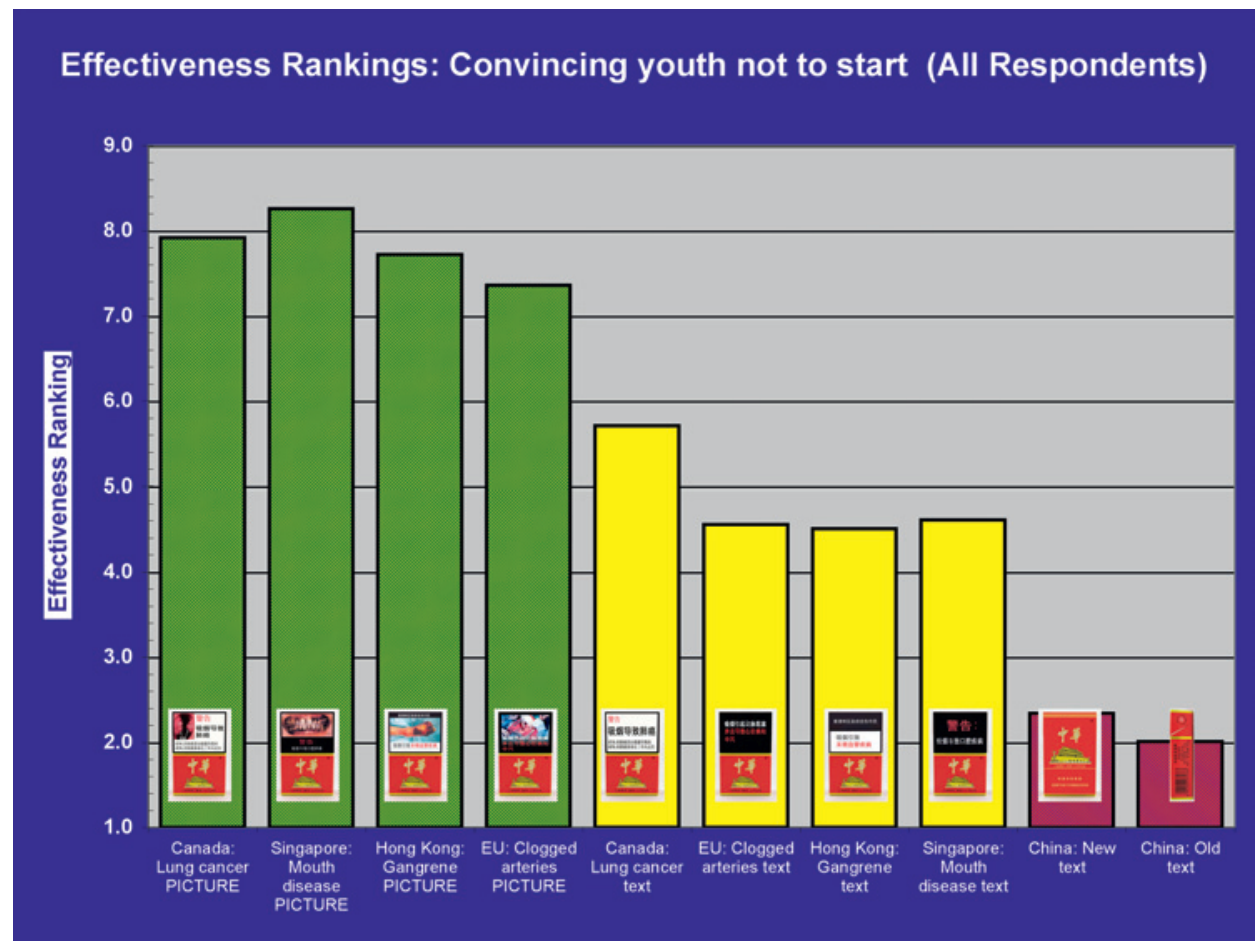


Figure 7 Mean ranking of health warnings on "How effective would each label be in informing the public about the harms of smoking?" (All Respondents).

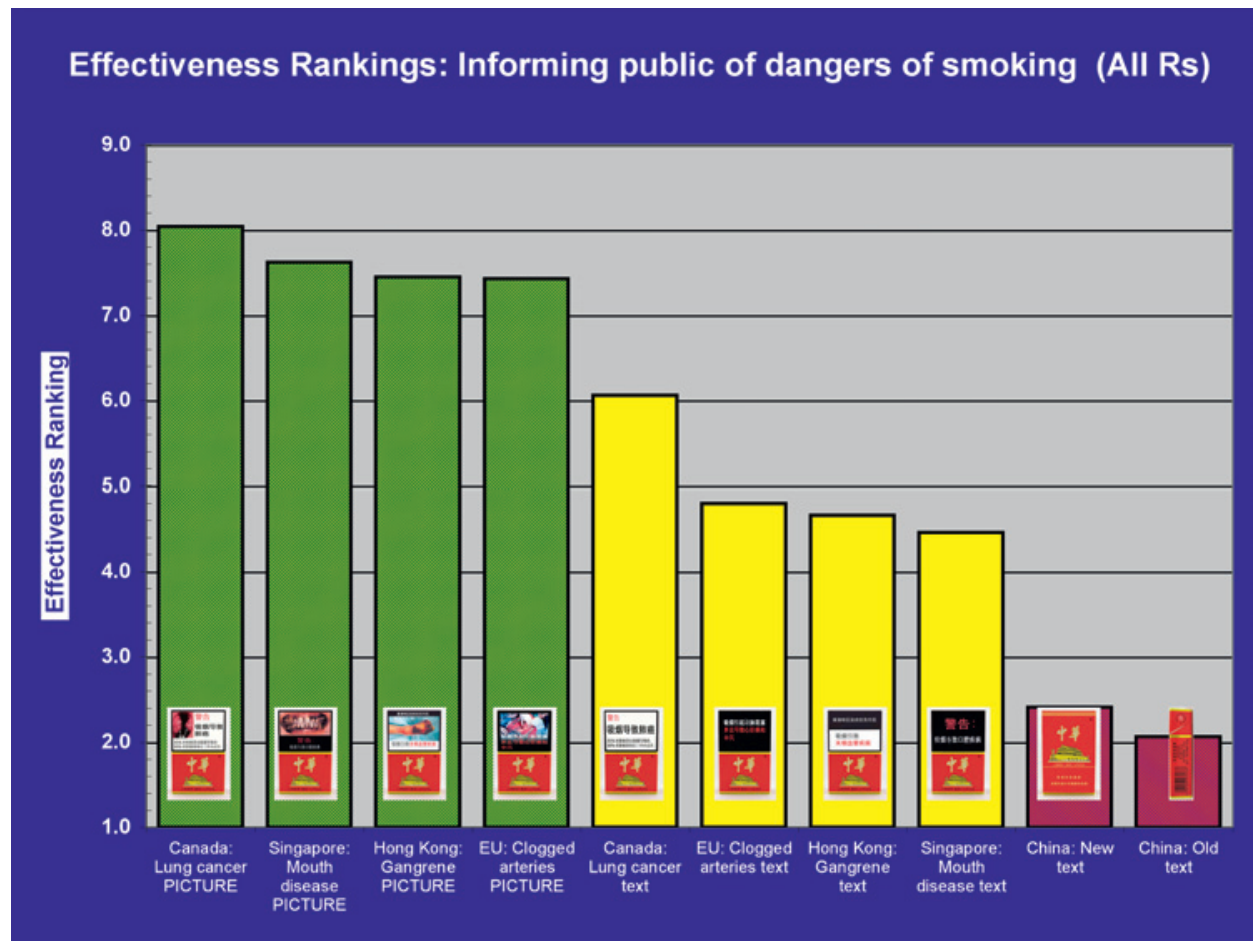

significantly higher than adult smokers $(p<0.001)$. However, it should be noted that even the majority of adult smokers wanted more health information on cigarette packages.

In addition, $80.7 \%$ of participants stated that warning labels should include pictures. This proportion was significantly higher among adult nonsmokers (86.1\%) than it was among youth (78.9\%) and adult smokers (77.4\%); both comparisons with nonsmokers: $p<0.025$. It was higher in Kunming (87.2\%) and Yinchuan (86.1\%) than it was in Beijing (77.6\%) and Shanghai (71.8\%); Beijing and Shanghai did not differ significantly from each other, but both were significantly lower than Yinchuan and Kunming ( $p<0.007$ for each comparison)

\section{Prevalence of understanding the English warning messages}

Table 3 presents the percentage of participants who correctly translated each of the two English phrases on the back of the cigarette pack. Of all adult smokers - the group that would be more likely to encounter these warnings - only $26.8 \%$ were able to correctly translate "smoking is harmful to your health" and only $10.1 \%$ could correctly translate "quit smoking early is
Figure 8 Mean ranking of health warnings on "How effective would each label be in showing that the Chinese Government is serious about reducing smoking?" (All Respondents).

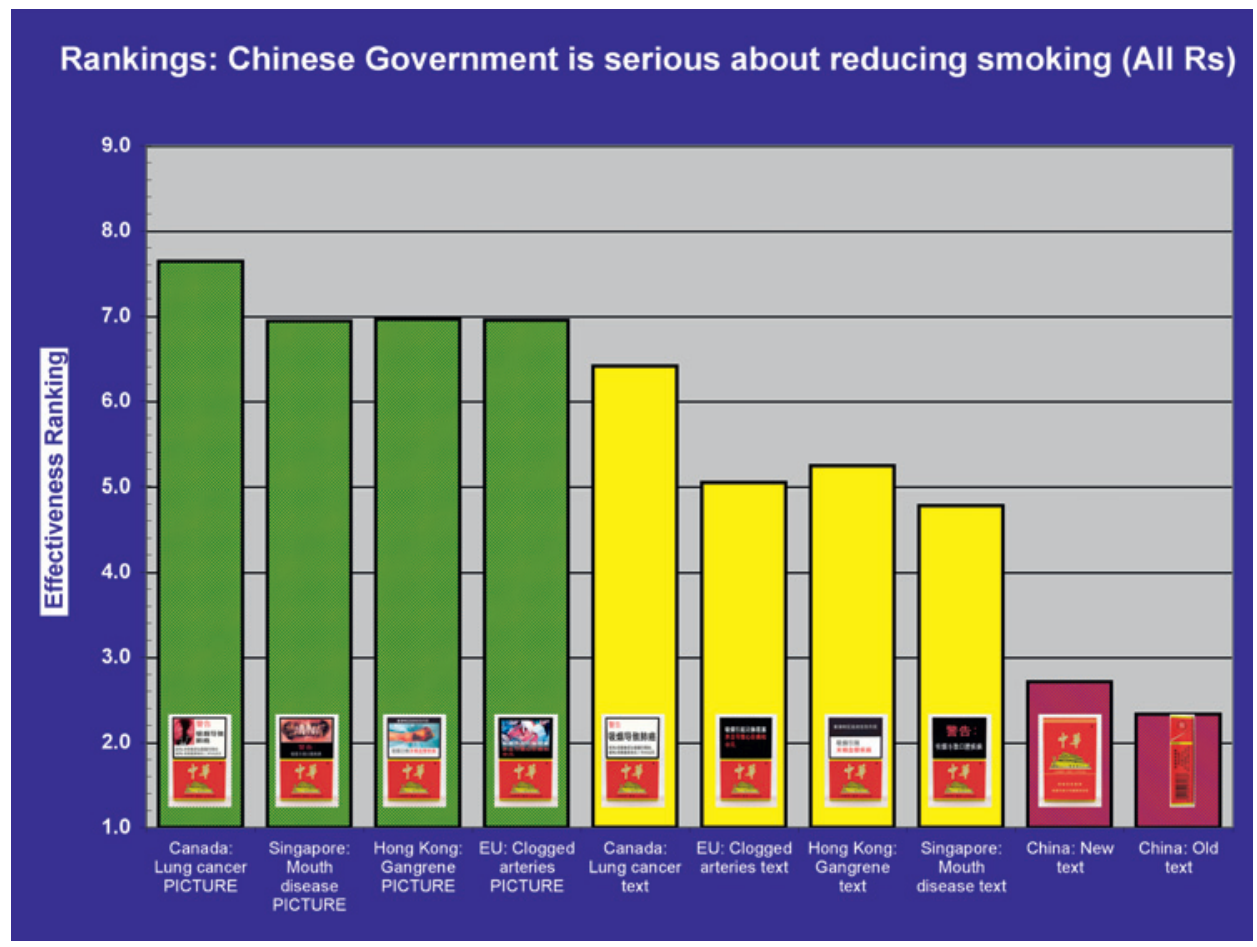


Table 3 Percentage of participants who correctly translated each of the two English warnings by type of participant

\begin{tabular}{lllll}
\hline & $\begin{array}{l}\text { Adult } \\
\text { smoker } \\
\text { (n=396) }\end{array}$ & $\begin{array}{l}\text { Adult } \\
\text { nonsmoker } \\
\text { (n=377) }\end{array}$ & $\begin{array}{l}\text { Youth } \\
\text { (n=396) }\end{array}$ & $\begin{array}{l}\text { Total } \\
\text { (n=1169) }\end{array}$ \\
\hline $\begin{array}{l}\text { "Smoking is harmful to your } \\
\text { health". }\end{array}$ & $26.8 \%$ & $51.5 \%$ & $90.4 \%$ & $56.3 \%$ \\
$\begin{array}{l}\text { "Quit smoking early is good } \\
\text { for your health". }\end{array}$ & $10.1 \%$ & $24.7 \%$ & $47.7 \%$ & $27.5 \%$ \\
\hline
\end{tabular}

good for your health". As expected, youth were more likely to be able to translate these English phrases $(p<0.0001)$, but fewer than half of youth $(47.7 \%)$ were able to translate the second phrase.

\section{DISCUSSION}

The results of this experimental study across a diverse set of people in four Chinese cities strongly support two conclusions: that picture warnings are judged as being more effective than text-only warnings and that the new China health warnings are judged as less effective than text-only warnings being used by other countries. These strong findings were highly consistent across the three participant groups (adult smokers, adult nonsmokers and youth), city and sex, as well as across all dimensions on which the effectiveness was being judged.

The two conclusions were supported on dimensions that are at the heart of the main objective of health warnings: to communicate effectively about the dangers of smoking. Much work in health communication has demonstrated that messages are stronger to the extent that they can provide specific information about harm and that they do so in a vivid and engaging manner. ${ }^{10} 11$ As of February 2010, 35 countries now employ pictorial warnings, ${ }^{12}$ which depict a broad range of specific harms that are caused by smoking, including lung cancer, heart disease, stroke, mouth disease, chronic obstructive pulmonary diseases (COPD, such as emphysema) and impotence. ${ }^{13}$ All of these adverse effects are well-documented by research, and some have been well-established for decades. As such, their inclusion on health warnings would be noncontroversial and important. Because knowledge of specific harms of smoking is low in China, ${ }^{14}$ findings from the ITC Four Country Survey (Canada, USA, UK and Australia) showing that health warnings have a beneficial impact on increasing knowledge about the risks of smoking $^{3}$ and of smoke constituents ${ }^{4} 15$ lead to the strong prediction that inclusion of such specific harms on health warnings would be an effective and low-cost method for increasing the knowledge of the Chinese public.

The findings make a compelling case that the Chinese health warnings introduced in October 2008 do not represent a significant enhancement. Both the old and the new warnings were consistently the lowest rated or ranked of the set of 10 warnings, and the new warning was only slightly stronger than the old warning, which had appeared on the side of the pack. The use of English for the warning on the back of the pack was shown to be ineffective at best: close to three-quarters of adult smokers could not translate one of the two sentences on the text-only warning, and close to $90 \%$ of them could not translate the other sentence. These findings support the principle that countries should not be presenting important health messages to their people in a foreign language.

The findings also indicate that the Chinese public wants their government to implement stronger health warnings. The vast majority wants more health information on cigarette packages, and an even greater proportion wants the health warnings to include pictures. This was true even among smokers. It should be noted that participants gave their responses to these two questions after seeing the picture warnings we had created for this study, so their opinions were shaped by having been exposed to concrete examples rather than by mere abstract concepts. It is also notable that participants in Kunming, located in the heart of the tobacco industry in China, were the highest among the four cities in their desire for the government to implement stronger health warnings.

\section{Limitations}

The experiment asked participants to give their opinions on the warnings after limited exposures, and thus the actual impact of the warnings if they were to appear on packs is not certain. Similar to this, the dependent measures were not actual risk perceptions, personal beliefs about smoking-related disease, quit intentions or smoking/quitting behaviour after having been exposed to real-world graphic warnings. Such a real-world experiment would be difficult or impossible to conduct. However, these findings of the superiority of pictorial warnings are convergent with findings from other experimental studies (eg, Peters $\mathrm{et}_{\mathrm{al}} \mathrm{l}^{9}$ ) and with population-based evaluations of warning labels from the ITC Project across a number of countries. ${ }^{13-8}$

This experiment was conducted in only urban areas and thus may not represent responses that would be obtained in rural areas. However, if literacy rate and knowledge of English are lower in rural China, then it is reasonable to expect that the main findings of the superiority of pictorial warnings and the low rates of comprehension of the English text would, if anything, be enhanced.

\section{Conclusions}

In response to the tobacco epidemic in China, which caused an estimated 673000 deaths in $2005,{ }^{16}$ China has made

\section{What this paper adds}

- Recent survey research and some experimental studies have demonstrated that including graphic pictures on health warnings on tobacco packaging is more effective in increasing thinking about the health risks of smoking and of motivating intentions to quit and actual quit attempts. These studies have almost exclusively been conducted in high-income countries.

- This is the first study to examine the potential impact of pictorial health warnings in China. Using an experimental design allowing the specific comparison of the same health warning with and without a graphic warning, the results demonstrated the superiority of pictorial health warnings; these results did not differ substantially across different cities, sex, smoking status and age group. Moreover, the inclusion of the old and new (October 2008) Chinese warnings allowed for an explicit comparison of the actual Chinese warnings against warnings from other countries. Both Chinese warnings were rated as lowest in effectiveness and the new warning was barely higher than the old warning in effectiveness. In all, the findings support the conclusion that the Chinese government's October 2008 enhancement of the warnings represents a minimal improvement over the old warnings and that pictorial warnings, such as those already introduced in 35 other countries, would represent a considerable improvement. 
a commitment towards tobacco control in its ratification of the FCTC. Strong health warnings are the foundation of a comprehensive approach to tobacco control because the objective of health warnings is to inform the public about the harms of tobacco products, using methods that will increase the likelihood that smokers will be motivated to quit and youth will be less likely to take up smoking.

The findings of this experimental study add to the growing evidence on the superiority of picture warnings and highlight the importance of strong, pictorial warnings in a comprehensive tobacco control program. But this study also demonstrates how little progress has been made so far in China on health warnings.

Note: Some of the results reported in this article were published in Chinese only in the Chinese Journal of Health Education under the following citation: Jiang, Y., Fong, G.T., Li, Q., Hammond, D., Quah, A.C.K., Yang, Y., Driezen, P., \& Yan, M. (2009). [Evaluation of the effectiveness of health warnings on cigarette packs in China, 2008]. Chinese Journal of Health Education [Chinese language], 25, 411-413, 430.

Acknowledgements We thank the local CDC and other groups and individuals in each of the four cities who assisted in the conduct of the study.

Funding This study was supported by a grant from the Bloomberg Initiative to Reduce Tobacco Use, through the Campaign for Tobacco-Free Kids. Additional support was provided by the Propel Centre for Population Health Impact at the University of Waterloo and by the Ontario Institute for Cancer Research.

Competing interests None

Ethics approval This study was conducted with the approval of the Institutional Review Board of the China National CDC and by the Human Research Ethics Committee at the University of Waterloo.

Contributors GTF led the conception and design of the study, the interpretation of the data analysis and drafted the article and its revisions. DH contributed to the conception and design, the interpretation of the data and revised drafts of the article. YJ contributed to the conception and design, the acquisition of data and reviewed drafts. OL contributed to the conception and design, to the acquisition of data and reviewed drafts. ACKO contributed to the conception and design and reviewed drafts. PD led the analyses of the data and reviewed drafts. MY contributed to the analyses of the data and reviewed drafts. All authors reviewed and approved the final version of the article.

Provenance and peer review Not commissioned; externally peer reviewed.

\section{REFERENCES}

1. Fong GT, Hammond D, Hitchman SC. The impact of graphic pictures on the effectiveness of tobacco health warnings. Bull World Health Org 2009;87:640-3.

2. FCTC Article 11 Guidelines. http://apps.who.int/gb/fctc/PDF/COp3/FCTC COP3 7 en.pdf.

3. Hammond D, Fong GT, McNeill A, et al. Effectiveness of cigarette warning labels in informing smokers about the risks of smoking: Findings from the International Tobacco Control (ITC) Four Country Survey. Tob Control 2006;15(Suppl 3):iii19-25

4. Hammond D, Fong GT, Borland R, et al. Text and graphic warnings on cigarette packages: Findings from the International Tobacco Control Four Country Study. Am J Prev Med 2007; 32:202-9.

5. Borland R, Wilson N, Fong GT, et al. Impact of graphic and text warnings on cigarette packs: Findings from four countries over five years. Tob Control 2009:18:358-64.

6. Borland R, Yong HH, Wilson N, et al. How reactions to cigarette packet health warnings influence quitting: Findings from the ITC Four Country Survey. Addiction 2009; 104:669-75.

7. Thrasher JF, Hammond D, Fong GT, et al. Smokers' reactions to cigarette package warnings with graphic imagery and with only text: A comparison of Mexico and Canada. Salud Publica Mex [Mexican J Pub Health] 2009:49(Suppl 2):S233-40.

8. International Tobacco Control Policy Evaluation Project. FCTC Article 11 Tobacco Warning Labels: Evidence and Recommendations From the ITC Project. Waterloo, Ontario, Canada: University of Waterloo, 2009. http://www.itcproject.org.

9. Peters E, Romer D, Slovic P, et al. The impact and acceptability of Canadian-style cigarette warning labels among U.S. smokers and nonsmokers. Nicotine Tob Res 2007:9:473-81.

10. Janis IL. Effects of fear arousal on attitude change: recent developments in theory and experimental research. In: Berkowitz L, ed, Advances in experimental social psychology, vol. 3. New York: Academic Press, 1967:166-225.

11. Witte K, Allen M. A meta-analysis of fear appeals: implications for effective public health campaigns. Health Educ Behav 2000;27:591-615.

12. Cunningham R. Cigarette package warning size and use of pictures: International summary. Canadian Cancer Society 2010

13. Cunningham R. Gruesome photos on cigarette packages reduce tobacco use. Bull World Health Organ 2009;87:569.

14. Yang J, Hammond D, Driezen P, et al. Health knowledge and perception of risk among Chinese smokers and non-smokers: Findings from the ITC China Survey. Tob Control 2010;19(Suppl 2):i40-i46.

15. Borland R, Yong $\mathrm{HH}$, Wilson $\mathrm{N}$, et al. How reactions to cigarette packet health warnings influence quitting: Findings from the ITC Four Country Survey. Addiction 2009;104:669-75.

16. Gu D, Kelly TN, Wu X, et al. Mortality attributable to smoking in China. N Engl J Med 2009:360:159-9. 